\author{
22-24 November, 2019 \\ Paris, France
}

\title{
Measurement of Heat Output of a Loop Heat Pipe with Radiation Heating
}

\author{
Peter Hrabovský ${ }^{1}$, Zuzana Kolková ${ }^{2}$, Zuzana Florková ${ }^{3}$, Mgr. Gabriela Belava ${ }^{4}$, Andrea \\ Dávidiková ${ }^{5}$ \\ University of Žilina, Research Centre, Univerzitná 8215/1, 01026 Žilina, Slovakia
}

\begin{abstract}
:
The paper focuses on the ways of heat transfer due to the phase-phase change from liquid to gaseous and vice versa. Described herein are heat transfer devices through a heat pipe and methods for transferring heat from a heat source to a point of consumption. A heat pipe is a device described in the literature as a material with more than 100 times higher thermal conductivity than copper. A heat pipe is an energy-efficient device without the need for an electrically powered element (circulation pump). The aim of this experiment is to construct a loop heat pipe device. Construction of the cooling circuit and ensuring sufficient cooling capacity by external cooling sources. Construction of a heating circuit in the form of a heat source and its regulation of heat output. Another objective is to measure the input and output parameters of the device and to calculate the resulting heat output of the loop heat pipe. The device itself is a cooling system for the removal of generated or waste heat from technological elements such as: electrical transformers, biomass and fossil fuel combustion processes, cooling of high-performance computer workstations, etc. Another objective is to select a suitable heat transfer medium. The right choice guarantees the optimal use of the loop heat pipe device in the optimum temperature working environment while minimizing the formation of noncondensable gases generated by the chemical reactions of the loop heat pipe material itself and the heat transfer medium. This selection greatly affects the cooling performance of the device.
\end{abstract}

Keywords: condensation; conductivity; evaporation; heat transfer; non-condensable gas 


\title{
$2^{\text {nd }}$ International Conference on Research in SCIENCE ENGINEERING AND TECHNOLOGY
}

\author{
22-24 November, 2019
}

\author{
Paris, France
}

\section{Introduction}

The HeatPipe is used to transfer heat (heat output) while maintaining a small temperature difference (Cheung, 1988). With this technology, it is possible to transfer a large volume of heat with small dimensions of the device. The device has no moving parts, is maintenance-free, with a very long service life (Chuang, 2003).

The heat pipe is a hermetically sealed system suitably filled with a working charge such as water, alcohol, Freon, mercury, ammonia, helium and the like. at a defined pressure (Cotter, 1967) (Zohuri, 2011). Heating the evaporating portion and cooling the condensing portion of the system causes the working medium to evaporate on the heated portion of the system, vapour flowing through the system to the cooled portion of the system, condensing back to the liquid and flowing back to the heated portion where it evaporates again (Faghri, 1995). This creates a forced circulation of the working medium associated with heat transfer (Grover, 1964).

\section{Experiment}

To determine the output of the heating device, a simple loop heat pipe model was constructed, which examined the performance parameters of the loop heat pipe for hot water heating.

The loop heat pipe model device is made of copper tubes and consists of three parts: the evaporation section, the transfer pipe (adiabatic section) and the condensation section of the heat pipe.

The evaporation part is located at the bottom of the heating device. It is made of copper pipe with a diameter of $22 \mathrm{~mm}$ and its length is $150 \mathrm{~mm}$. Part of the evaporation part is an electric heating element which envelops the evaporation part and serves as a source of thermal energy for heat transfer. In the evaporation part of the loop heat pipe there is a phase change of the working substance from the steam state to the liquid state.

Figure 1: Sectional view of the heating element and evaporative part of the loop heat pipe.

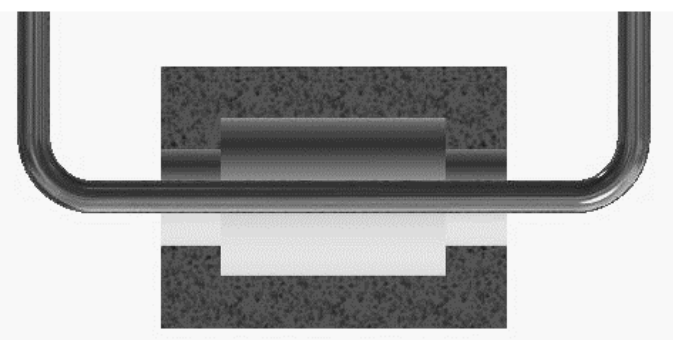

The condensation section is located at the top of the heating device. It is made of a tube-intube heat exchanger. The inner tube with a diameter of $22 \mathrm{~mm}$ and a length of $240 \mathrm{~mm}$ represents the condensation part of the loop heat pipe in which the vapour phase condenses to liquid. This phase process releases latent heat and heats hot water by passing heat through the copper tube. An outer pipe with a diameter of $55 \mathrm{~mm}$ and a length of $240 \mathrm{~mm}$ delimits the space between the inner and outer pipe, which serves as a heat exchanger for hot water heating. The 
function of this space is to dissipate heat from the heat pipe condenser, thereby cooling the loop heat pipe and heating the hot water. The total volume of the heat exchanger is $438 \mathrm{ml}$.

Figure 2: Sectional view of the heat exchanger and the condensing part of the loop heat pipe.

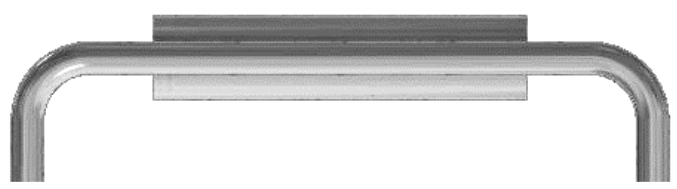

The transfer pipe that connects the evaporation and condensation part of the loop heat pipe is made of copper pipes with a diameter of $22 \mathrm{~mm}$ and a total length of $1210 \mathrm{~mm}$. Individual copper joints are soldered with a hard tin solder material.

Figure 3: The real state of the loop heat pipe model before and after the insulation with armaflex thermal insulation

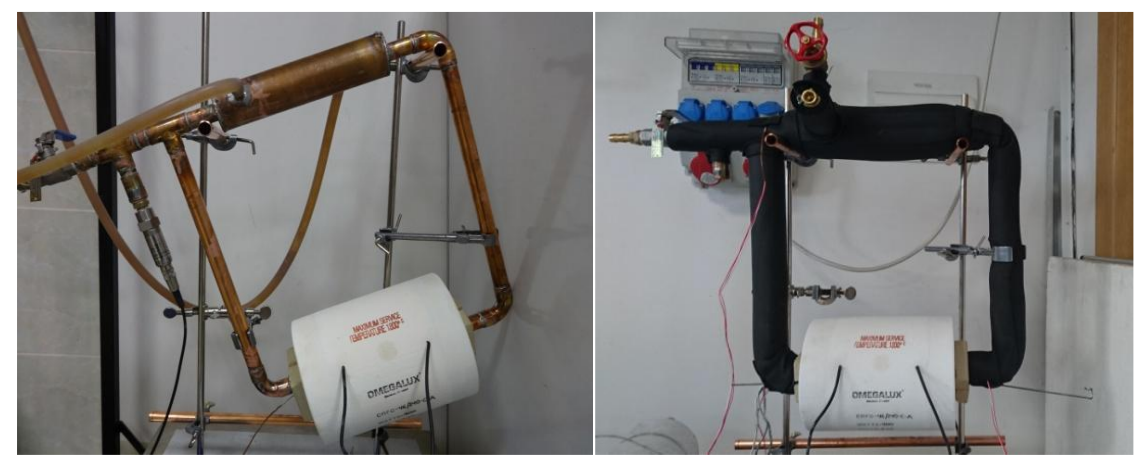

Heat transfer medium resp. the working substance of the loop heat pipe is distilled water (Ku, 1999). Temperature sensors are located at the inlets and outlets of the individual parts of the loop heat pipe and the heat exchanger. In the upper part is located a pressure sensor and a valve, which serves to fill and empty the volume of the loop thermal tube with the working substance.

On the circuit between the heat exchanger and the circulating thermostat there is a flowmeter for measuring the flow of heated water. The flow rate is controlled with a precise flow rate setting of $0.03 \mathrm{dm} 3 . \mathrm{s}-1$ using a heart valve. The heat output supplied by the electric heater was measured by a power measuring device of independent power supply devices. 


\section{$2^{\text {nd }}$ International Conference on Research in SCIENCE ENGINEERING AND TECHNOLOGY}

Figure 4: Model experimental heating equipment.

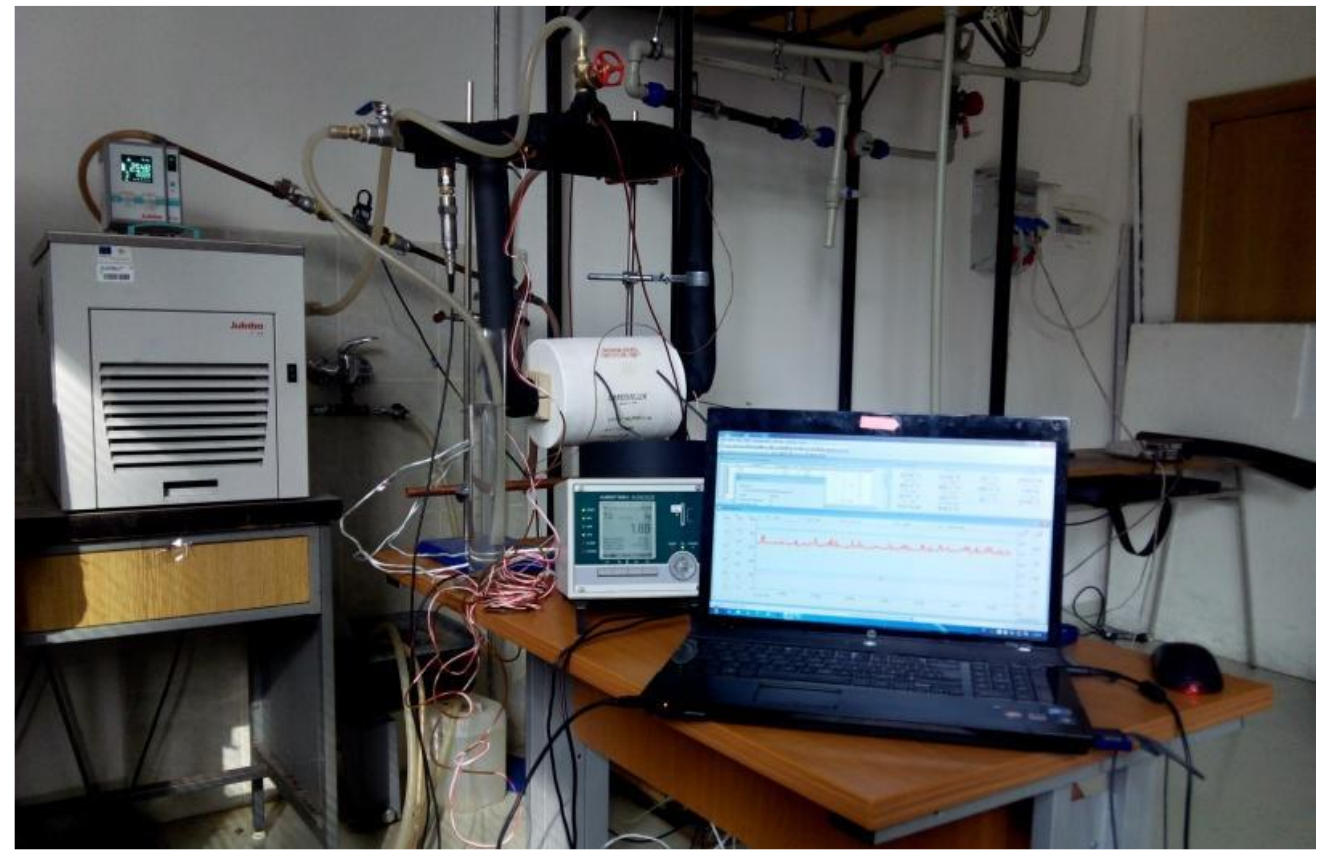

Figure 5: Experimental device wiring diagram.

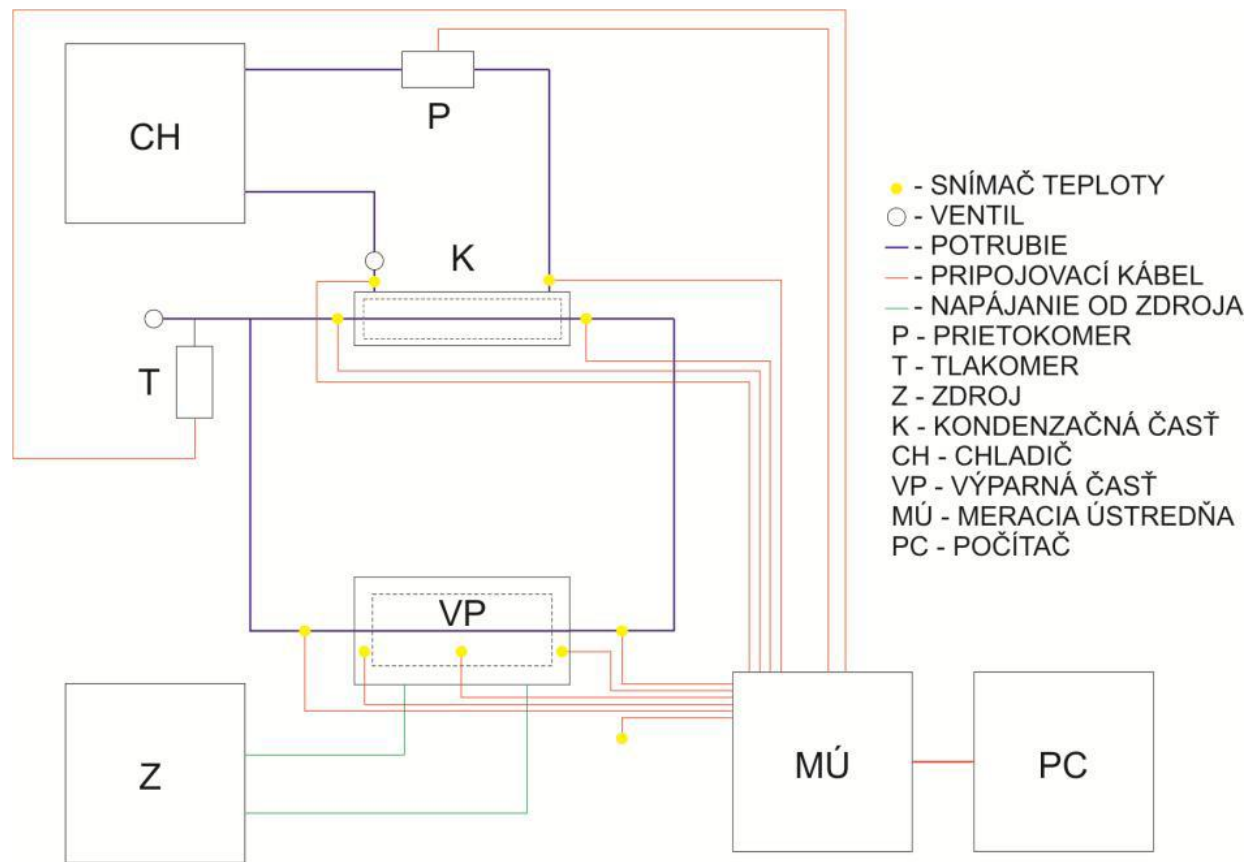

The evaporation part was heated by means of an electric heating cylinder connected to the auto transformer, on which the value of the output voltage in the range from 150 to $260 \mathrm{~V}$ was controlled in $30 \mathrm{~V}$ steps. The output power from the heating cylinder was measured using a 
single-phase active power converter that is connected between the heating cylinder and the auto transformer. The actual value of the heating cylinder power is recorded by interfacing with the control panel. Inside the cylinder are three high temperature resistant $\mathrm{NiCrNi}$ temperature sensors. Other temperature sensors (Pt100) were located at the inlet and outlet of the evaporator.

The condensation part is connected to the heat exchanger of the tube-in-tube structure, which serves to remove the transferred heat through the heat pipe by means of cooling water. The heat exchanger is connected to a Julabo circulating thermostat, which continuously maintains the cooling water temperature at $20^{\circ} \mathrm{C}$. The cooling water flow rate was set to $0.03 \mathrm{dm} 3 \cdot \mathrm{s}-1 \mathrm{using}$ a heart valve. At the outlet of the heat exchanger there is a flowmeter that records the flow of cooling water. Pt100 temperature sensors are located at the inlet and outlet in the exchanger, which sense the temperature of the cooling water. Temperature sensors are located in front of and behind the condensation part of the loop heat pipe. Based on the values obtained, the transferred heat output was determined, which was transferred through the loop heat pipe from the evaporation to the condensation section. A pressure sensor was placed downstream of the condensation section on the transfer line to measure the actual pressure inside the loop heat pipe during cyclic heat transfer from the evaporation to the condensation section.

For the evaluation of the measured data, the calorimetric method (Eq. 1) shall be used to determine the power transferred through the loop heat pipe (Lee, 2010). For individual temperature-dependent elements (i.e., coolant heat capacity and density), a parametric equation obtained from a graphical representation of temperature versus heat capacity and density is used. The calorimetric equation has the form:

$$
Q=\dot{m} \times c \times d T\left[J . s^{-1}=W\right]
$$

Where the mass flow is given by Eq. 2:

$$
\dot{m}=\dot{V} \times \rho\left[\mathrm{kg} \cdot \mathrm{s}^{-1}\right]
$$

To calculate mass flow, the value for density and specific heat capacity of the liquid was calculated as a function of temperature.

Figure 6: Graphs of heat pipe performance, hot water inlet and outlet temperature at $150 \mathrm{~V}, 170 \mathrm{~V}$ input voltage.

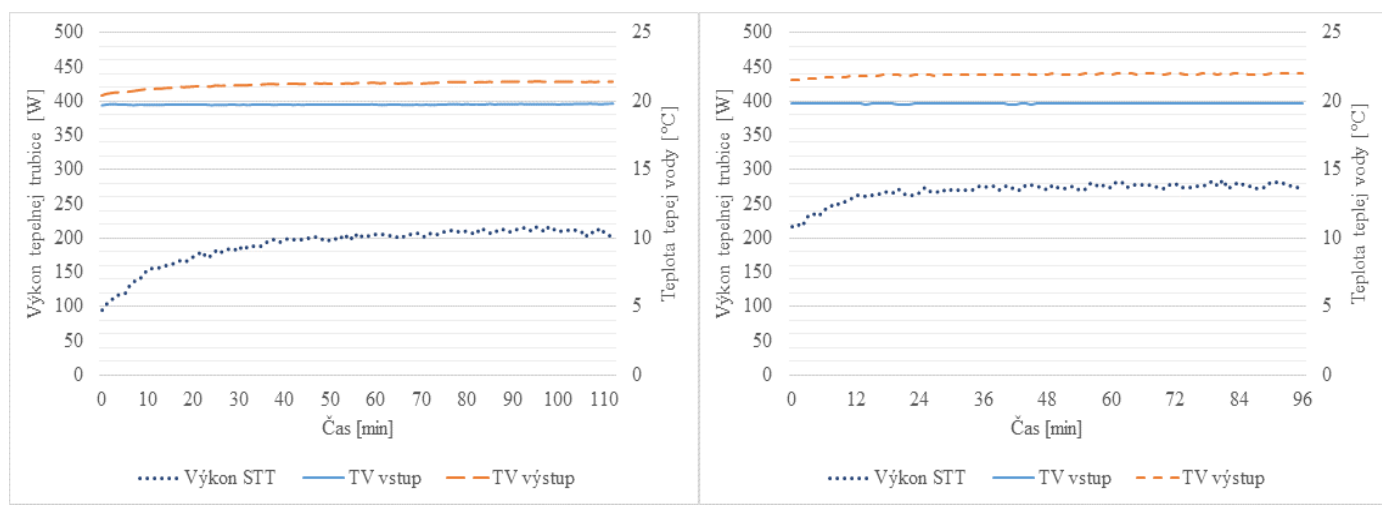


Figure 7: Graphs of heat pipe performance, hot water inlet and outlet temperature at 190V, 210V input voltage.

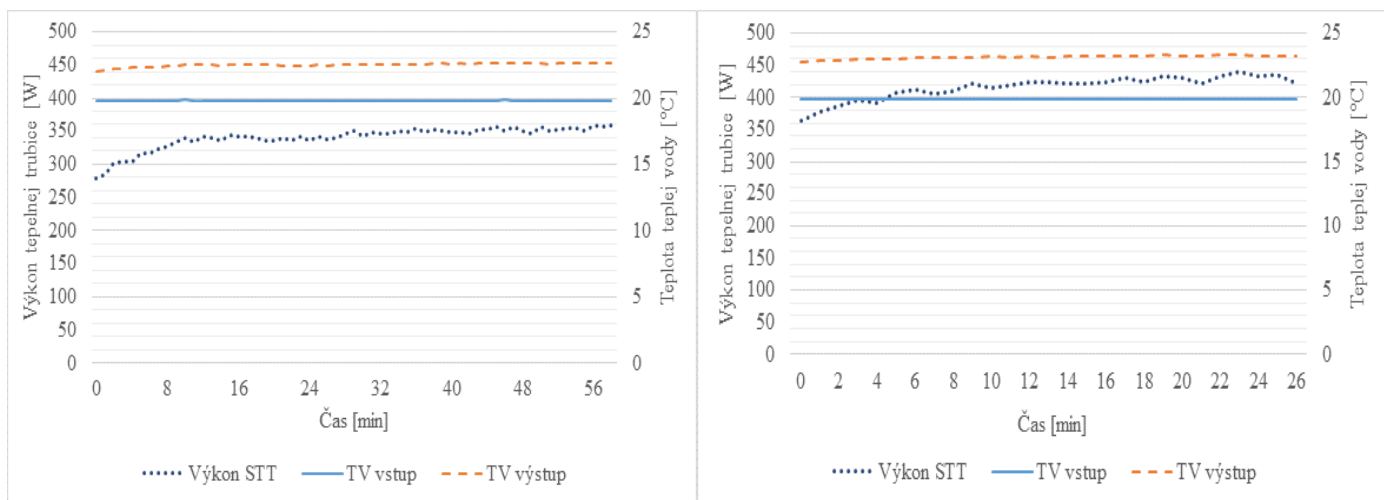

Figure 8: Graphs of heat pipe performance, hot water inlet and outlet temperature at $230 \mathrm{~V}, 250 \mathrm{~V}$ input voltage.
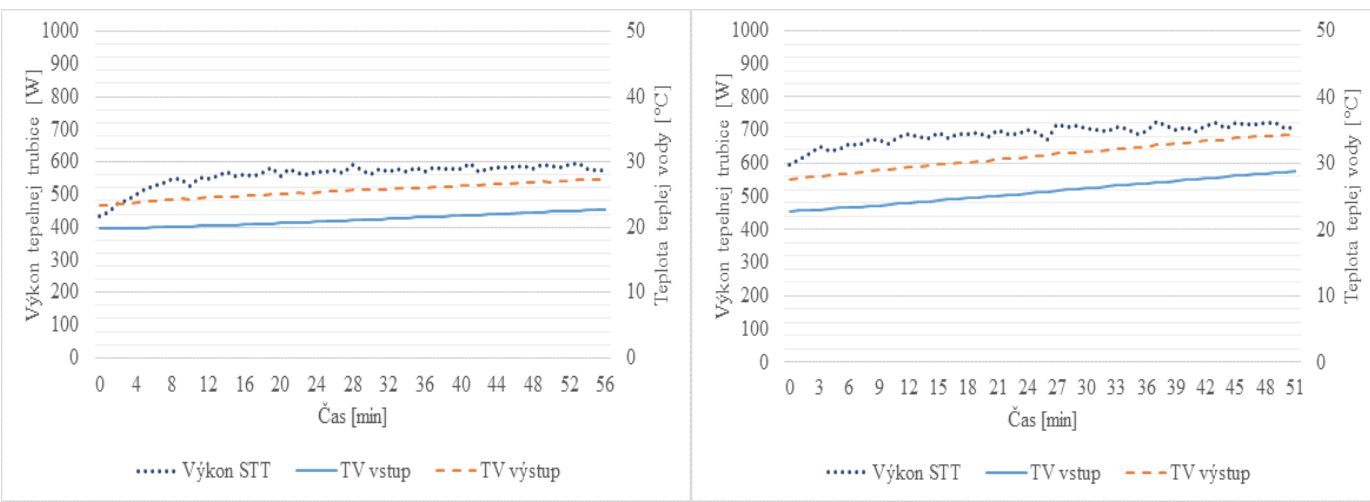

In the Figures (Figure 58 - Figure 63), a graphical waveform of the model loop thermal experimental device at each of the preset values of the input voltage to the heat source $(150$, $170,190,210,230,250 \mathrm{~V}$ ) is shown. Table 6 contains the values from the measurement of the model loop thermal test device during steady state.

Table 1: Measurement data from a model experimental loop heat pipe device

\begin{tabular}{|l|l|l|l|l|l|}
\hline $\begin{array}{l}\text { Input } \\
\text { voltage } \\
\text { value }\end{array}$ & $\begin{array}{l}\text { Outlet cooling } \\
\text { water temperature }\end{array}$ & $\begin{array}{l}\text { Inlet cooling water } \\
\text { temperature }\end{array}$ & $\begin{array}{l}\text { Cooling water } \\
\text { temperature difference }\end{array}$ & $\begin{array}{l}\text { Cooling water } \\
\text { flow }\end{array}$ & $\begin{array}{l}\text { LHP } \\
\text { performance }\end{array}$ \\
\hline$[\mathrm{V}]$ & {$\left[{ }^{\circ} \mathrm{C}\right]$} & {$\left[{ }^{\circ} \mathrm{C}\right]$} & {$\left[{ }^{\circ} \mathrm{C}\right]$} & {$[$ liter.min-1] } & {$[\mathrm{W}]$} \\
\hline 150 & 21,41 & 19,77 & 1,64 & 1,83 & 209,73 \\
\hline 170 & 21,99 & 19,82 & 2,18 & 1,82 & 276,79 \\
\hline 190 & 22,59 & 19,81 & 2,79 & 1,81 & 351,87 \\
\hline 210 & 23,25 & 19,84 & 3,41 & 1,81 & 431,21 \\
\hline 230 & 27,24 & 22,65 & 4,59 & 1,81 & 580,95 \\
\hline 250 & 34,23 & 28,64 & 5,59 & 1,82 & 709,92 \\
\hline
\end{tabular}


The experiment was run according to the specified sequence of consecutive steps. Initially, a loop heat pipe was designed and constructed, which serves to transfer heat by changing the latent phase of the hot water working medium. The heat exchanger was provided by a heat exchanger which includes the condensation part of the loop heat pipe (Reay, 2006). At the start of the measurement, the heat exchanger was allowed to cool to a constant temperature of $20^{\circ}$ C. Then the default value of the heat source input voltage was set. After the temperature in the exchanger has stabilized, this input voltage value has increased by $20 \mathrm{~V}$. During the whole experiment the individual quantities (temperature, flow, pressure ...) were recorded by the control panel to the computer.

\section{Conclusion}

The experiment shows the ability of heat transfer and hot water heating under continuous heating. As can be seen from the measurement graphs, the cooling device, which is also designed for flow-through cooling, was unable to cool the circulating cooling water at higher power outputs. Therefore, the inlet temperature of the cooling water increased.

\section{Acknowledgment}

„This work was supported under the project of Operational Programme Research and Innovation: Research and development activities of the University of Zilina in the Industry of 21 st century in the field of materials and nanotechnologies, No. 313011T426. The project is cofunding by European Regional Development Fund. 


\section{References}

[1] Cheung, M. K. et al., (1988). Thermal Performance and Operational Charakteristics of Loop Heat Pipe. Proceedings of the 28th International Conference on Environmental Systems, Society of Automotive Engineers, (SAE Paper No. 981813).

[2] Chuang, P. A., (2003). An Improved Steady-state Model of Loop Heat Pipes Based on Experimental and Theoretical Analyses.: ProQues.

[3] Cotter, T. P., (1967). Heat Pipe Startup Dynamics. Proceeding SAE Thermionic Conversion Specialist Conference, Palo Alto, CA.

[4] Faghri, A. (1995). Heat pipe: science and technology. Global Digital Press.

[5] Grover, G. M. et al., (1964). Structures of Very High Thermal Conductivity. Journal of Applied Physics, Vol. 35, pp. 1190-1191.

[6] Ku, J., (1999). Operating Characteristics of Loop Heat Pipes. Proceedings of the 29th Internationl Conference on Environmental Systems, Society of Automotive Engineers, Denver, CO (SAE Paper No. 1999-01-2007).

[7] Lee, H. (2010). Thermal design: heat sinks, thermoelectrics, compact heat exchangers, and solar cells. New Jersey: John Wiley \& Sons.

[8] Reay, D. et al., (2006). Heat Pipes: Theory, Design and Applications. 5. ButterworthHeinemann.

[9] Zohuri, B. (2011). Heat pipe design and technology: a practical approach. Boca Raton: Taylor \& Francis Group. 